\title{
Keipert syndrome
}

INSERM

\section{Source}

INSERM. (1999). Orphanet: an online rare disease and orphan drug data base. Keipert syndrome. ORPHA:2662

Keipert syndrome is a rare multiple cong enital anomalies syndrome characterized by facial dysmorphism (hypertelorism, broad and high nasal bridge, depressed nasal ridge, short columella, underdeveloped maxilla, and prominent cupid-bow upper lip vermillion), mild to severe congenital sensorineural hearing loss, and skeletal abnormalities consisting of brachytelephalangy and broad thumbs and halluces with large, rounded epiphyses. Additional manifestations that have been reported include pulmonary valve stenosis, voice hoarseness and renal agenesis. 